\title{
¿Espacios libres en (la) transición? La primera Semana Grande de Bilbao ${ }^{1}$
}

\author{
Free areas in (the) transition. The first Bilbao's Great Week
}

Raúl López Romo • exposicion@centromemorialvt.com

CENTRO PARA LA MEMORIA DE LAS VÍCTIMAS DEL TERRORISMO

Recibido: $26 / 12 / 2017$

Aceptado: 16/01/2018

\section{Resumen}

Este artículo se centra en las fiestas de Bilbao de agosto de 1978 para, partiendo de ese caso particular, extraer una lectura de ciertas prácticas colectivas en el marco de la transición española a la democracia. La Aste Nagusia (Semana Grande), aprovechando las grietas del sistema, favoreció la visibilidad de una sociedad civil emergente. Ello se consiguió mediante la ocupación masiva y alegre de la calle. No obstante, espacios libres como las fiestas de las que aquí tratamos, terminarían convirtiéndose en ámbitos donde el nacionalismo vasco radical volcó su apología del terrorismo de ETA.

Palabras clave: Espacios libres, transición, País Vasco, fiestas, Bilbao.

\section{Abstract}

This article deals with the festivities of Bilbao in August 1978 in order to examine certain collective practices in the context of the Spanish transition to democracy. The Aste Nagusia (Great Week) favored the visibility of an upcoming civil society. This was achieved by the occupation of the streets. However, these free spaces like the festivities of Bilbao became also the site where radical Basque nationalism defended ETA's terrorism.

Keywords: Free spaces, democratic transition, Basque Country, festivities, Bilbao.

\footnotetext{
${ }^{1}$ Una primera versión de este texto fue presentada en el VIII Congreso de la Asociación de Historia Contemporánea, celebrado en Vitoria-Gasteiz en septiembre de 2006. Agradezco a Barbara van der Leeuw, Gaizka Fernández Soldevilla, José Antonio Pérez, Santiago Burutxaga, Gorka Angulo y Pilar Pérez-Fuentes su lectura y sugerencias. Elaborado en el grupo de investigación IT-708-13, dirigido por Luis Castells (UPV/EHU).
} 


\section{UNA SEMANA DE NUEVE DÍAS}

«Las fiestas populares de Bilbao, un éxito de la espontaneidad». Así titulaba su contraportada El País del 29 de agosto de 1978, haciéndose eco de una satisfacción general que quedaba plasmada en la prensa del momento. Y en la entradilla se añadía un dato ilustrativo: «intervinieron más de un millón de personas». Por su parte, los eufóricos organizadores señalaban en Egin que «al calor de esta popularidad, reconocemos con orgullo de bilbaínos y de vascos que nuestras fiestas han supuesto un éxito colectivo que hemos materializado con la generosa, directa y entusiasta participación del pueblo»².

Imagen 1. Toro ensogado, 27-08-1978. Archivo Municipal de Bilbao (AMB). Fondo de La Gaceta del Norte

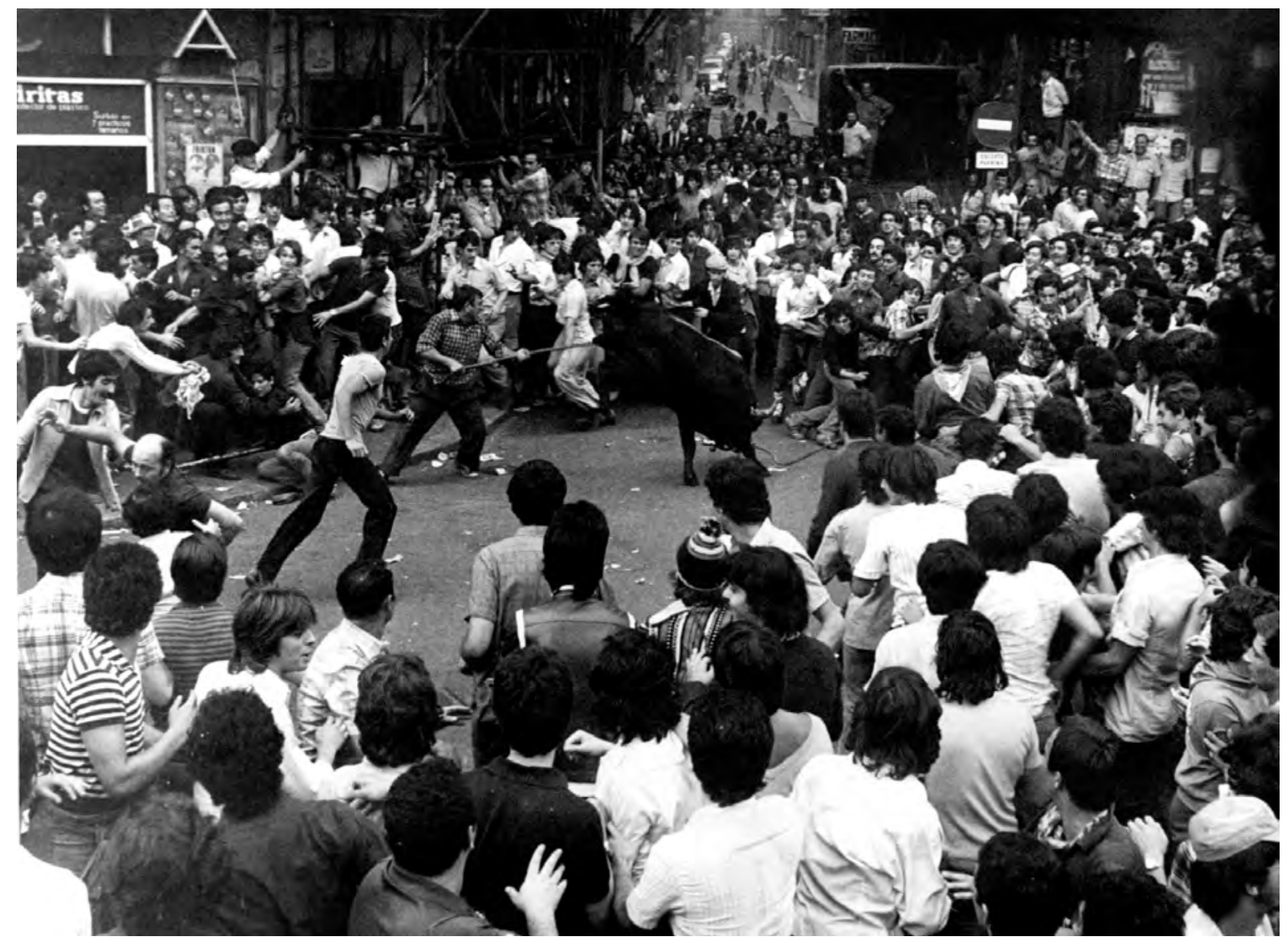

Quedaban atrás nueve días de Aste Nagusia (Semana Grande) en los que «nunca el pueblo se divirtió más». Desde el sábado 19 de agosto la zona del Casco Viejo y el Arenal se había convertido en centro neurálgico multitudinario y multifuncional. Allí se tocaba diana y tenía lugar el tradicional toro ensogado o sokamuturra, que juntaba al amanecer a miles de personas, trasnochadoras y madrugadoras. La mañana continuaba con juegos infantiles en la Plaza Nueva, para dar paso al mediodía a la música de la Banda Municipal, bajo

2 El País, 29 de agosto de 1978. Egin, 27 de agosto de 1978. 
¿Espacios libres en (la) transición? La primera Semana Grande de Bilbao | Raúl López Romo

la batuta de don Urbano Ruiz Laorden. Como apuntaba El Correo, «jamás el maestro habrá tenido tantos oyentes en los conciertos de la afamada, sufrida y nunca bien ponderada Banda». Por la tarde, las corridas en la plaza de toros de Vista Alegre centraban la atención. Como grata novedad se mencionaba la presencia «de un millar, aproximadamente, de jóvenes que animaron la tarde» en un coso con fama de serio. «Los componentes de las charangas y sus cuadrillas hicieron una presentación magnífica. Su alegría, sus canciones, su mejor humor sirvieron para amenizar esos minutos de descanso entre toro y toro» ${ }^{3}$.

Imagen 2. Bajada de las comparsas hacia el Arenal, 26-08-1978. AMB. Fondo de La Gaceta del Norte

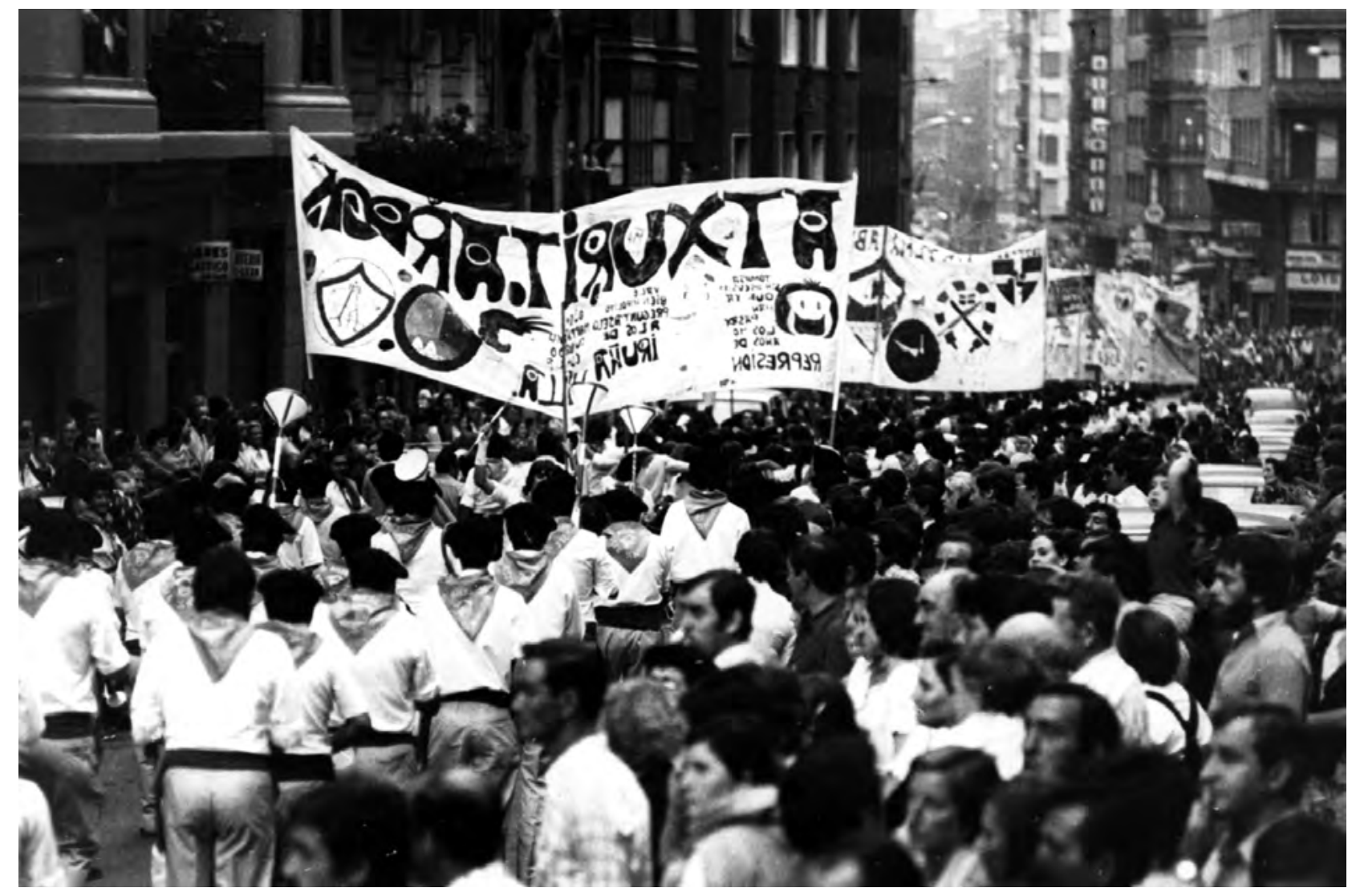

En torno a las 20:00 horas, las cuadrillas, agrupadas en comparsas, desfilaban «entre el júbilo de todos los presentes» desde la plaza de toros hasta el Arenal al son de la música de las fanfarrias. Ya de nuevo en el recinto festivo, obras de teatro (tanto callejero como en el Arriaga), toros de fuego y romerías amenizaban la velada hasta altas horas de la madrugada. "La noche en Bilbao, en sus casi primeras fiestas - explicaba El Correo-, la inicia principalmente la verbena. Cada una, animada por grupos de música que se adaptan no solo a los estilos y épocas, sino que al mismo tiempo han tenido en cuenta los gustos y las edades (...) para todos ha tenido un punto de aliciente en común: disfrutar y vivir una verbena, cosa difícil, y hasta diríamos que original en una gran ciudad como Bilbao» .

\footnotetext{
${ }^{3}$ El Correo, 23 de agosto de 1978. El Correo, 22 de agosto de 1978.

${ }^{4}$ El Correo, 22 de agosto de 1978. El Correo, 23 de agosto de 1978.
} 
Al día siguiente comenzaba de nuevo el ritual con escasas variaciones, puesto que el programa no contaba con alardes espectaculares ni cantidad de actos simultáneos. En diferentes días sí se celebró un festival de bertsolaris, improvisadores de versos en euskera, que reunió a las figuras más destacadas del momento (procedentes de Vizcaya, Guipúzcoa y el País Vasco francés, se dieron cita Amuriza, Azpillaga, Lopategui, Aguirre, Lazcano, Lizano, Ezponda y Xanpun), exhibiciones de deporte rural vasco y alardes de danzas tradicionales, una carrera ciclista, un día del disfraz o la «I Bandera Villa de Bilbao» de traineras. Pero, en sustancia, la fiesta consistía en la presencia masiva de la ciudadanía en la calle o, mejor dicho, en algunas calles: «Todo Bilbao era un desierto (...). El Arenal, sin embargo, estaba al completo. Como a todas horas» ${ }^{5}$. Todo ello, tras décadas sin festejos dignos de tal nombre ${ }^{6}$.

Imagen 3. Aurresku de honor ante la Basílica de Begoña, 16-08-1978. AMB. Fondo de La Gaceta del Norte

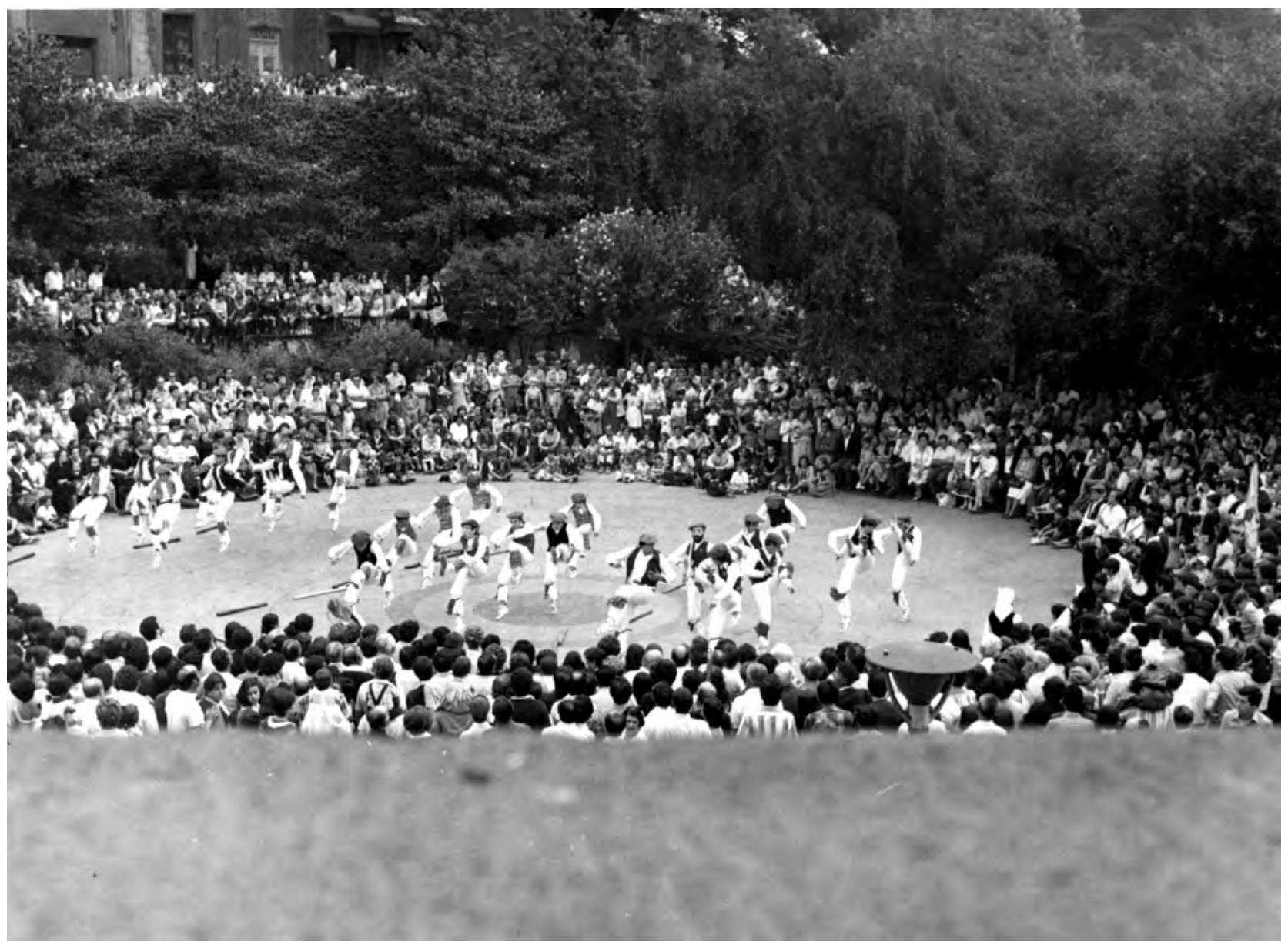

Durante el franquismo, los actos festivos, de escaso arraigo y de carácter habitualmente elitista, se concentraban en espacios cerrados en torno a tres grandes ejes: toros, ópera y teatro ${ }^{7}$. Mientras, «al pueblo llano no le quedaba apenas otro recurso que las barracas. In-

\footnotetext{
${ }^{5}$ El Correo, 22 de agosto de 1978.

${ }^{6} \mathrm{http}: / /$ www.bilbaopedia.info/semana-grande-bilbao

7 Sobre las fiestas durante la primera mitad de los 70, AMB, Sección Festejos (RE 2/2004), Legajo Letra C, p. 26.
} 
cluso los fuegos artificiales y las verbenas se dejaron perder como festejos impropios de una ciudad $»^{8}$. En la prensa clandestina, el Partido Comunista había denunciado ya en fechas tempranas (1946) la utilización por parte de las autoridades de las fiestas patronales «como ejemplo de la feliz y sana alegría de un pueblo que recoge las bienandanzas repartidas a voleo por Franco (...). Estas fiestas bajo el franquismo han perdido el color y la fuerza vital que antes tenían y en muchos casos, como en los hechos recientes de Fuenterrabía, las fiestas se convierten en nuevos días de terror y de represión»${ }^{9}$.

En una sociedad como la vasca, golpeada por el fenómeno omnipresente de la violencia, de cara a las fiestas de 1978 «desde los distintos frentes de la ciudad, incluso desde los que se muestran políticamente más activos, se ha insistido en la necesidad de que las fiestas transcurran con normalidad, ya que no en balde se trata de la primera ocasión que tienen los vecinos de Bilbao de celebrar sus fiestas en la calle» ${ }^{10}$. Si bien es cierto que hubo algún intento de desestabilizar los actos por parte de incontrolados de extrema derecha (hubo amenazas de atacar las txoznas y se incendió una imprenta anarquista ${ }^{11}$ ), el suceso local que puso la nota más triste fue el fallecimiento de un chico, José Ignacio del Río, durante el curso de una sokamuturra. El desgraciado accidente se produjo al quedar el joven atrapado bajo una marquesina de autobús que se vino abajo por el peso de la gente encaramada a ella ${ }^{12}$.

Si a la altura de 1978 las fuerzas más dinámicas de Bilbao, procedentes de diversos sectores políticos y sociales, convergieron en un mismo fenómeno - mediante un sentido compartido de la fiesta y de la reivindicación-, conviene ahora trazar un guion que contextualice y haga comprensible el episodio en un marco general. Un esquema que, además, siga la pista a las complicidades que se establecieron entre los diferentes protagonistas y que, en fin, explique cómo en este caso concreto «la cotidianeidad burla con sus tácticas sutiles, ingeniosas y flexibles - patrimonio de la cultura popular - las estrategias anquilosadas de las instituciones que representan a los diversos poderes» (Gracia Cárcamo, 1995: 201).

Así pues, ¿cómo se organizaron las fiestas? ¿Quién estaba al frente del Ayuntamiento? ¿Cuál era el contexto en el País Vasco del momento?

\section{EL ACONTECIMIENTO EN SU CONTEXTO}

Las fiestas tienen siempre una relación profunda con el tiempo. En la base de las fiestas hay siempre una concepción determinada y concreta del tiempo natural (cósmico), biológico e histórico. Además, las fiestas, en todas sus fases históricas, han es-

\footnotetext{
${ }^{8}$ El País, 29 de agosto de 1978.

9 «El perfil actual de las tradicionales fiestas populares», Euskadi Roja, 22 de agosto de 1946.

10 El País, 20 de agosto de 1978.

${ }^{11}$ El País, 25 de agosto de 1978 y Egin, 29 de agosto de 1978.

12 «Las fiestas de luto», tituló en su primera página El Correo del 24 de agosto de 1978.
} 
tado ligadas a periodos de crisis, de trastorno, en la vida de la naturaleza, de la sociedad y del hombre. (Bajtin, 1971: 14)

Partiendo de esta observación, que parece aquí especialmente pertinente, vayamos profundizando en el caso que nos ocupa. En España, la persistencia de una dictadura retrasó la libre expresión de la pluralidad política varias décadas con respecto al discurrir de la Europa liberal. Los sectores más activos de la oposición, que hasta 1977 permanecieron fuera de la legalidad o bien habían ido apareciendo discretamente aprovechando pequeños resquicios de permisividad, venían erosionando al régimen manteniendo una dinámica de conflictividad permanente que hacía de la "paz» franquista una mera ilusión propagandística (Fusi, 1986 y Heine, 1986). Pero fue solo a partir de 1976 cuando se presentó la oportunidad de que toda una serie de grupos subterráneos - muchas veces vinculados a las transformaciones experimentadas en el campo de la izquierda durante los años 50 y 60 a nivel internacional, especialmente en torno a los acontecimientos de un 68 cuya herencia se reivindicaba - florecieran, planteando abiertamente sus demandas.

Centrándonos ya en el País Vasco, en los terrenos de la cultura y la política emergieron por doquier partidos de «nueva izquierda» (ORT, Organización Revolucionaria de Trabajadores, LCR-LKI, Liga Comunista Revolucionaria, MCE, Movimiento Comunista de España...), movimientos sociales de nuevo cuño (feminista, gay, antinuclear, vecinal), grupos contraculturales con un sentido alternativo de las artes o de la fiesta, revistas satíricas como Euskadi Sioux (nacida en 1979), grupos de música como Oskorri, que bebían tanto de la música popular vasca como de la canción protesta americana contra la guerra de Vietnam, compañías de teatro con una vocación provocadora, como Cómicos de la Legua - Kilikilariak, que participaban en festivales ajenos a los circuitos comerciales con un marcado acento político, etc. ${ }^{13}$

De todo ese entramado político, social y cultural, minoritario y a menudo estrechamente interrelacionado, surgió la fuerza necesaria para llevar adelante la primera Aste Nagusia al margen tanto del discurso conservador como de una izquierda tradicional que pronto se institucionalizaría. No en vano, la fiesta de 1978 reunió en su primera comisión organizadora a Natxo de Felipe (cantante de Oskorri), a Santiago Burutxaga (actor de Cómicos de la Legua) y su cartel anunciador fue obra de Juan Carlos Eguillor (posteriormente en Euskadi Sioux).

Echemos un poco la vista atrás para comprobar cuál era la situación previa a 1978. He consultado informes que elaboraba la Policía a finales del franquismo y a comienzos de la transición, dando cuenta de las incidencias diarias de orden público en Vizcaya ${ }^{14}$. Lo que centraba el interés de cara a la represión eran los asuntos laborales (conflictividad obrera, paros, elecciones sindicales), la actividad de las organizaciones terroristas (principalmente

\footnotetext{
13 Oskorri significa «cielo rojo» y Kilikilariak puede traducirse como «excitadores».

${ }_{14}$ Archivo del Gobierno Civil de Vizcaya. Partes policiales diarios correspondientes a 1975 y 1976.
} 
de ETA) y la de los partidos opositores, la contestación entre los estudiantes y el clero, y el fenómeno del «separatismo» (así, en genérico). En ese periodo las fiestas patronales no permanecieron al margen de los crecientes movimientos de protesta. Algunas fueron utilizadas como plataformas de expresión de demandas contrarias al régimen. Como señala Mikel Aizpuru, el nacionalismo vasco había enraizado en diversas manifestaciones del folclore permitido (danzas, romerías), lo que le ayudó a multiplicarse y afirmarse en tiempos de dictadura. Tanto en Cataluña como en el País Vasco las fiestas se politizaron ya en la crisis del franquismo y sobre todo durante la transición (Aizpuru, 1997: 486).

Imagen 4. Cartel de la Aste Nagusia de 1978, obra del artista Juan Carlos Eguillor

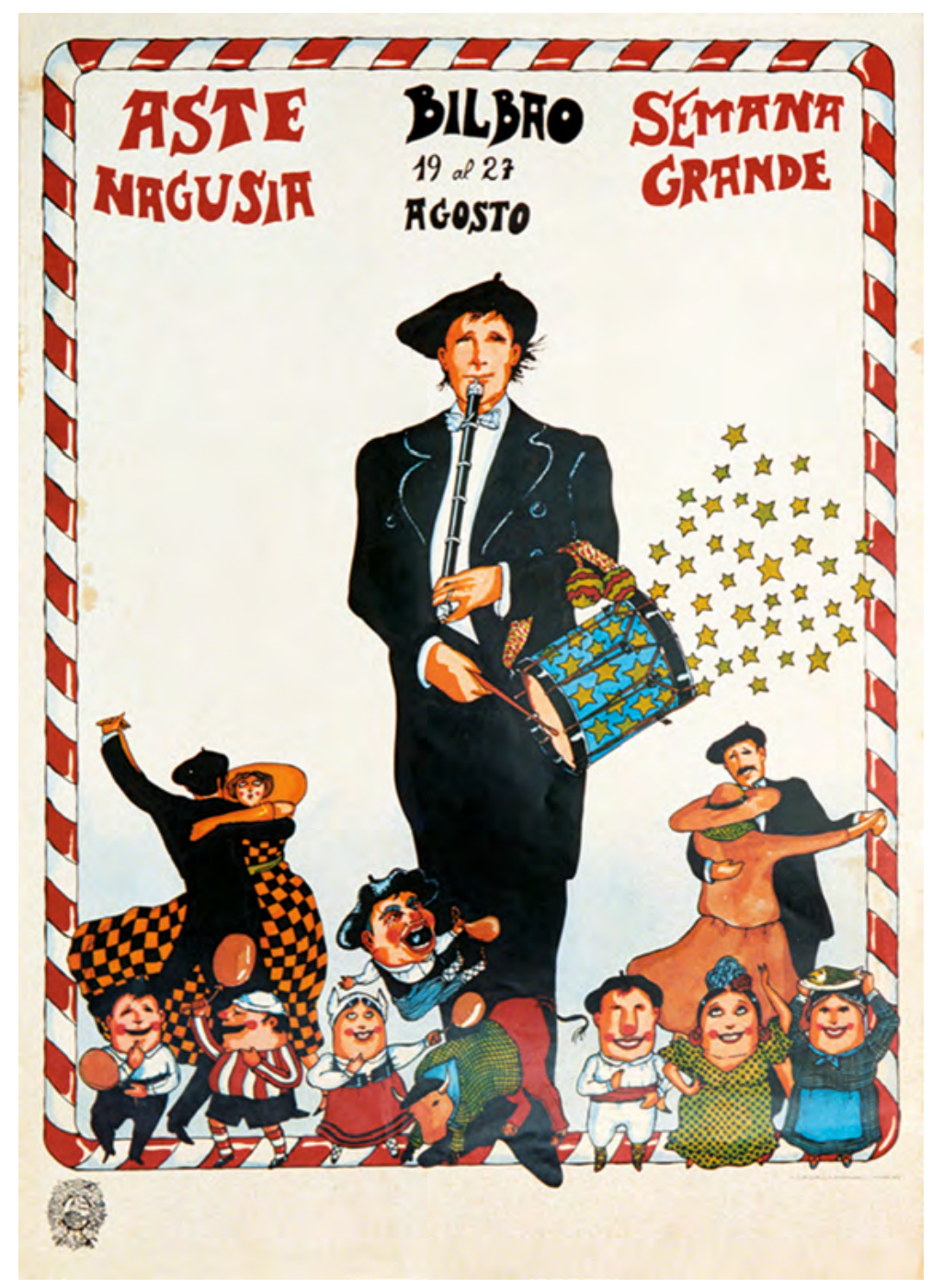

Fuente: Euskal Museoa-Bilbao-Museo Vasco.

Veamos varios ejemplos. El 1 de agosto de 1975 la ORT aprovechó la concentración de público en las fiestas de San Ignacio (Bilbao) para lanzar propaganda contra las penas de muerte impuestas a José Antonio Garmendia y Ángel Otaegi, miembros de ETA políticomilitar. Dos semanas más tarde, tanto en Gernika como en Bilbao las comisiones de barrios llamaron al boicot de las fiestas de esas localidades y pidieron la disolución de las 
FOP. Ese llamamiento se repitió en septiembre en las fiestas de Leioa y en octubre en las de San Fausto (Basauri), donde fueron colocados carteles agitando temas de interés local.

En el verano de 1976 el contexto era diferente. Franco había muerto en noviembre del año anterior, la transición daba sus primeros pasos y las fuerzas de la oposición se manifestaban cada vez más abiertamente. Frente a ellas, empezó a actuar un tipo de terrorismo de extrema derecha que pretendía que nada cambiara. El 9 de julio de 1976, en el Día de la Sardina (una celebración de Santurtzi), pistoleros de ultraderecha mataron a una ama de casa, Normi Menchaca, tras una manifestación pro-amnistía. En los días siguientes, otras fiestas, como las de Trapagaran o Arrigorriaga, fueron aprovechadas para protestar por este suceso. En Arrigorriaga también apareció propaganda del PSOE por una Euskadi socialista y libre, y del MCE en conmemoración del primer centenario de la abolición de los fueros. Entre julio y agosto hubo numerosas manifestaciones coincidiendo con las fiestas de Bermeo, Sestao, Gorliz, Amorebieta, Getxo, Lemoa, Ondarroa o Portugalete: se colocaban ikurriñas (aún ilegales), se proferían gritos a favor de «Pertur», miembro de ETApm desaparecido, de «gora Euskadi askatuta» (viva Euskadi libre) o "presoak kalera» (los presos a la calle). Todas estas incidencias eran reportadas por la Policía, que se mostraba incapaz de frenarlas. En las páginas de El País, el periodista Jesús Ceberio informaba de que «parece claro que sigue adelante el intento de aprovechar las fiestas populares vascas, como marco para expresar peticiones políticas que tal vez no encuentran todavía cauces apropiados de expresión» ${ }^{15}$.

Como ha resumido el historiador Luis Castells, «a un tiempo oscuro en el que las ansias de cambio estaban aplastadas por el régimen franquista, le siguió una etapa caracterizada por la explosión de libertad, de alegría y de un entusiasmo que, sin embargo, pronto trocó en el País Vasco en desazón, desasosiego, confrontación (...). Con un telón de fondo en el que la violencia y el terrorismo formaban parte del escenario cotidiano. De esta forma, lo que se había imaginado que sería un tiempo de encuentro y reconciliación, resultó en el País Vasco un periodo en el que la libertad se fue estableciendo con dolor, sufrimiento y muchas víctimas» (Castells, 2017: 67). En efecto, a lo largo de los años de la transición ETA incrementó su desafío terrorista, alcanzando unas cotas inéditas. En 1975 ETA asesinó a 14 personas, que ascendieron a 17 en 1976, 11 en 1977, 66 en 1978, 80 en 1979 y 96 en 1980, el año más sangriento (López Romo, 2015).

Pese a todas las dificultades, la transición española siguió adelante gracias a la combinación de iniciativas «desde arriba» y «desde abajo»: pactos entre las fuerzas políticas democráticas y presión de la calle. Ahora bien, a diferencia de lo que ocurría en el resto del país, en Euskadi una parte de esa presión adquirió una vertiente des-democratizadora, al incluir numerosas muestras de apoyo a la violencia de ETA (López Romo, 2011). En suma, la transición no fue un proceso inmaculado ni pacífico, particularmente en el País Vasco, pero también aquí la libertad se fue abriendo paso paulatinamente y eso pudo atisbarse a nivel local (Toral, 2015).

${ }^{15}$ El País, 1 de agosto de 1976. 


\section{LOS PREPARATIVOS}

Con sus cerca de 450.000 habitantes, el Bilbao de los primeros años 70 era una urbe de tamaño medio-grande y el mayor centro industrial de la cornisa cantábrica. Pero en ella empezaban a notarse los efectos de la crisis económica. El crecimiento poblacional iba frenándose progresivamente y a partir de 1977 ya se aprecia un ligero retroceso, más acentuado durante los años siguientes merced a un saldo migratorio negativo ${ }^{16}$. En 1978, la última corporación municipal procedente del franquismo padecía un importante déficit de legitimidad. Si bien se habían celebrado elecciones generales el 15 de junio del 77, los ayuntamientos aún no se habían democratizado. Paralelamente a esta situación, el potente movimiento vecinal de la capital vizcaína, surgido en la década de 1960, venía presionando al Consistorio mediante diferentes iniciativas (Urrutia, 1985; Pérez, 2001: 93-97). Desde la reclamación de mejores infraestructuras en los barrios (urbanización, transportes, educación...), hasta la exigencia de información, participación en los plenos y, finalmente, la dimisión de alcalde y concejales, y la formación de una gestora que gobernara el municipio en espera de la convocatoria de comicios libres. El salto cualitativo de las asociaciones vecinales ha sido señalado para el conjunto de España mediante una fórmula gráfica: «empezaron reclamando semáforos o asistencia sanitaria y acabaron reivindicando ayuntamientos democráticos» (Molinero e Ysàs, 1992: 275). En el caso de Bilbao, El libro negro de Recaldeberri es un buen compendio de los males que aquejaban a aquella villa gris, sucia y decadente, así como de los intentos de su movimiento vecinal por darles solución (Asociación de Familias de Recaldeberri, 1975).

Entre 1977 y 1979 se multiplicaron las solicitudes de aulas en los colegios nacionales para impartir clases de euskera en horario extraescolar (en Atxuri o Zurbaran), de locales para organizar guarderías y jardines de infancia (San Ignacio), de bibliotecas (Bolueta, Loiu), de instalaciones deportivas (Zorroza, Rekaldeberri), etc. ${ }^{17}$. Todo ello da fe de una notable efervescencia que aprovechaba los aún estrechos intersticios del sistema para evidenciar las contradicciones existentes y canalizar reivindicaciones que las instituciones no recogían, planteando alternativas a nivel autoorganizativo (Levi, 2003: 135 y 136). Entre 1975 y 1979 fue alcalde de Bilbao José Luis Berasategui Goicoechea, quien, pese a estar al frente de la última corporación de la dictadura, fue, en palabras de Joseba Egiraun y Javier del Vigo, «un hombre comprensivo con los nuevos tiempos» (Egiraun y del Vigo, 2007: 129).

En este contexto, a iniciativa de Quico Mochales, relaciones públicas de El Corte Inglés, se convocó en marzo de 1978 el concurso «Hagamos populares las fiestas de Bilbao», bajo el patrocinio de esa empresa. Se trataba de incorporar a la mayoría de la población a unos festejos hasta entonces deslucidos. Las asociaciones de vecinos venían defendiendo en los barrios un modelo de fiestas «participativo». Tras superar recelos iniciales, decidie-

\footnotetext{
${ }^{16}$ AMB, Memorias Municipales, años 1975 a 1983 [en 1978 y 1979 no se realizaron].

17 Véase al respecto, por ejemplo, los informes de la comisión de cultura correspondientes a los años 1977 , 1978 y 1979, en AMB, RE 7/2004, 29364, 29365 y 29366 respectivamente.
} 
ron colaborar puesto que el concurso parecía ofrecer suficientes garantías de transparencia, como relata la representante de dichas asociaciones en la primera comisión de fiestas (Lanciano en VV.AA., 1993: 16 y 17). El día 9 de junio, el jurado, formado por cuatro representantes del Ayuntamiento y otros tantos del movimiento vecinal, se reunió en la Casa Consistorial para publicar el fallo. Tras larga votación, entre los 37 trabajos presentados se eligió combinar dos propuestas. Por un lado, la presentada por «Chimbo Zarra», al 25\%. Por otra parte, el 75\% restante quedaría para el proyecto del «experto y profundo conocedor del tema "Txomin Barullo»», seudónimo tras el que realmente se encontraba la comisión de arte y cultura de Euskadiko Mugimendu Komunista (EMK, Movimiento Comunista de Euskadi).

«Txomin Barullo» era el apodo de Domingo de Sagarminaga, «notable organizador» de festejos y procesiones en el Bilbao de finales del xix. Según recuerda Santiago Burutxaga, se tomó su nombre por varios motivos. Primero, porque era «sonoro y divertido». Segundo, porque juntaba castellano y euskera. Tercero, por recuperar a un bilbaíno chirene, que aunaba una curiosa doble faceta de promotor de celebraciones profanas y sagradas ${ }^{18}$. Ahora se apostaba por hacer «cultura popular». En palabras de Peter Burke:

La cultura popular no es exclusiva como la alta cultura. Está abierta a todos, como la taberna o la plaza del mercado donde tuvieron lugar tradicionalmente tantas actuaciones. ¿Podemos excluir tan siquiera a la elite social y política? Quizá tengan una cultura propia cerrada, pero esto no les ha impedido siempre participar en el Carnaval... (Burke, 1991: 153.155)

Los miembros de «Txomin Barullo» se pusieron inmediatamente a trabajar para materializar el proyecto, en el que finalmente no se reflejó ese $25 \%$ inicialmente reservado para «Chimbo Zarra». La primera iniciativa que se tomó fue sumar fuerzas mediante la celebración de una asamblea en los locales de la biblioteca municipal de Bidebarrieta. Se convocó a ella a representantes de las casas regionales, grupos deportivos, culturales, teatrales, políticos, asociaciones de vecinos, grupos de danzas... de la villa, para que se implicaran y, así, la sociedad civil recuperara protagonismo. Según Álvaro Gurrea, profesor, economista y entonces miembro del Movimiento Comunista: "vino mucha gente, de todos los partidos (apenas representación del PCE ni del PSOE), y los medios de comunicación. Ese día a la noche estaba ya montada la comisión de fiestas con amplia representación popular y al día siguiente los medios lo daban como noticia importante» (Golvano, 2004: 99). Se contaba con apenas dos meses, «muchísimos ánimos y poquísimos medios» (Lanciano en VV.AA., 1993: 16) para que todo quedase dispuesto. El presupuesto aprobado por el Ayuntamiento fue de ocho millones de pesetas. A título orientativo diremos que en las fiestas de 1977 se invirtió una cantidad similar, pese a que la asistencia fue mucho menor. El dinero destinado al festival de ópera rondaba los 30 millones de pesetas.

18 Email de Santiago Burutxaga al autor, 27/12/2017. 
El proyecto que servía de guion no establecía un cuerpo cerrado de actividades, sino que facilitaba un marco para el desenvolvimiento de las ideas; una vía «de carácter abierto y flexible» a través de la cual todos los bilbaínos podían colaborar y sentir como propias sus fiestas, dejando así de ser meros consumidores o espectadores pasivos: «Creemos, pues, unos cauces adecuados en los que pueda manifestarse todo el rico caudal de la expresión popular y habrá fiesta. En caso contrario, la suma de espectáculos podrá como mucho constituir un «epatante» alarde de medios, pero el pueblo permanecerá mudo, quizá impresionado pero inexpresivo; no habrá actuado y lo aplausos corteses con que despida a quienes vinieron a divertirle serán también una velada forma de manifestar su frustración» ${ }^{19}$.

Imagen 5. Pegatina de la Aste Nagusia de 1978.

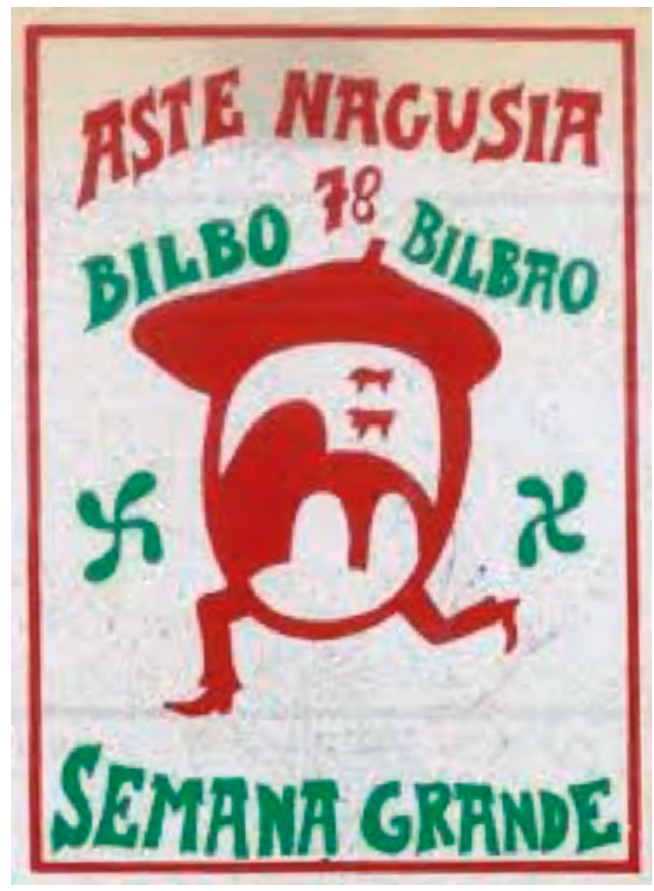

Fuente: Fundación Sancho el Sabio. Base de datos de pegatinas.

Al mismo tiempo, se hizo un esfuerzo por bucear en la tradición festiva bilbaína para crear algo nuevo con anclajes en el pasado. De este modo, se recogieron las fechas (la segunda quincena de agosto, marcada por la feria taurina), los toros, el deporte, los gigantes y cabezudos, y el Gargantúa. A todo ello se le añadió conceptos novedosos, que hacían de la participación y de la creatividad el lugar central. Ahora bien, la fiesta tiene sus propios códigos. Romperlos supone excluir, organizar actos para el disfrute o para la publicidad de un grupo particular. El objetivo ahora era integrar a todo el «pueblo», entendiéndolo como algo variado, dividido por la edad, el lugar de procedencia, las diferencias económicas, las ocupaciones laborales, el sexo... 
Para no dispersar a los participantes se decidió centralizar los actos en un único espacio que, por ser el núcleo originario de la villa (el Casco Viejo-Arenal), tenía para sus habitantes un vínculo sentimental. Se trataba de ocupar masivamente la calle en una explosión licenciosa (Homobono, 1982). Una puesta en escena magnífica, por todo lo que implicaba de recuperar un paisaje urbano cerrado durante varios días al tráfico. Allí, la gran mayoría de las actividades eran gratuitas. Centralizar los actos, pero descentralizar la organización. Al margen de la comisión de fiestas, se hizo un llamamiento a la población para crear comisiones por barrios. Cuadrillas de amigos, organizaciones de movimientos sociales, asociaciones de diferentes tipos, partidos políticos, etc., respondieron entusiastamente y se fueron organizando en comparsas. Cada una había de contar con un mínimo de 50 personas, que compartirían trajes de una misma clase, y con una fanfarria, conjunto musical a base de instrumentos de metal y percusión. El término procede del verbo «fanfarrear», hablar con arrogancia, con bravatas y jactancias..., clave etimológica de su estruendosa aparición callejera. Asimismo, cada una levantaría su txozna o caseta en el recinto festivo. Un espacio con barra abierta a la calle, al entorno y al alterne.

Imagen 6. Montaje de las primeras txoznas para la Aste Nagusia, 19-08-1978. AMB. Fondo de La Gaceta del Norte

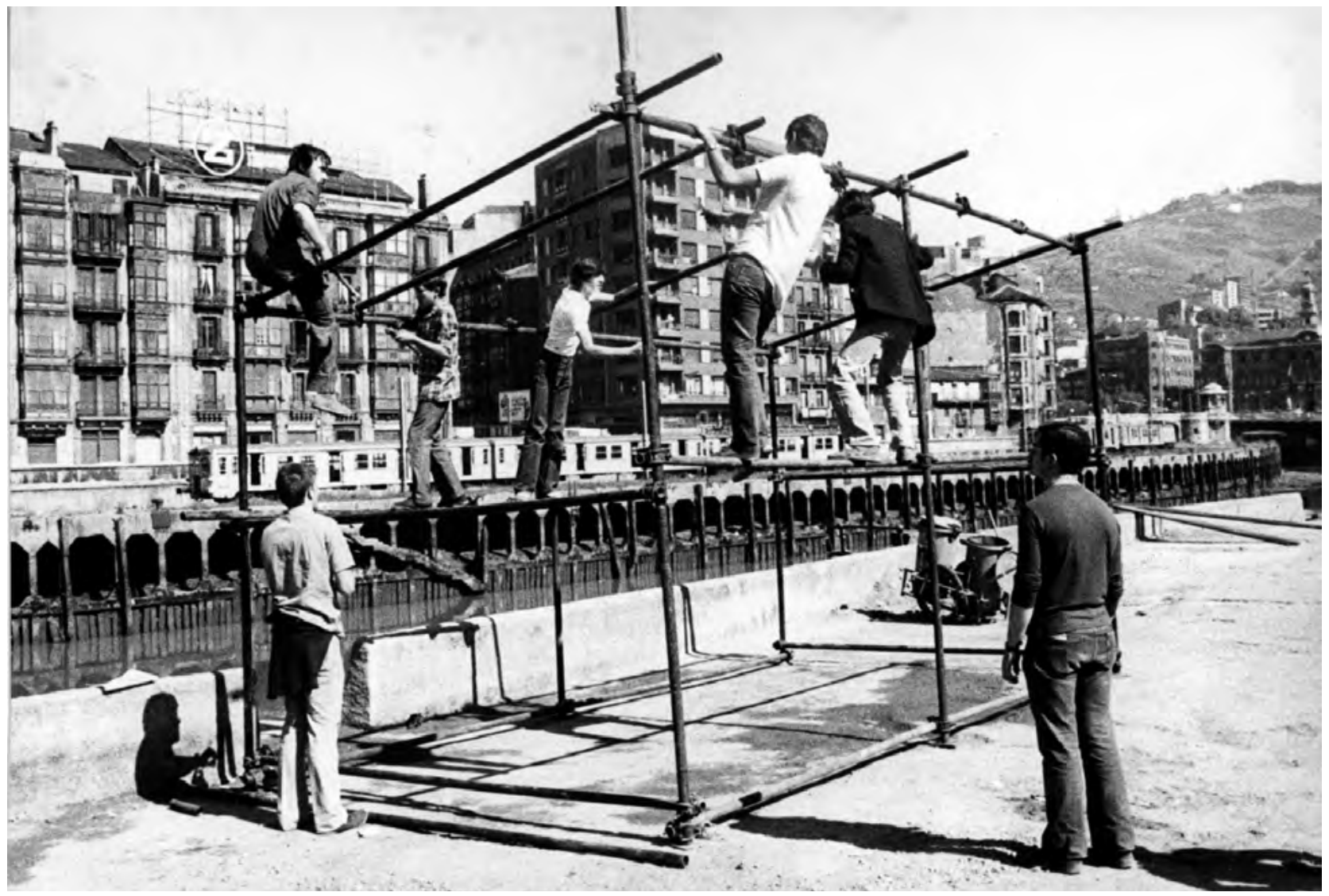

La preexistencia de cuadrillas, que en muchos casos no solo compartían amistad, sino también militancia político-social, fue, por tanto, un elemento clave para dinamizar las comparsas en particular y las propias fiestas en general. El fenómeno de las cuadrillas en Euskadi ha sido estudiado por diferentes autores, que han subrayado su contribución a la 
revitalización de las identidades locales y, también, su importancia para la continuidad de ideologías proscritas bajo la dictadura (Ramírez, 1984; Pérez-Agote, 1987).

Tabla 1. Relación de comparsas para la primera Aste Nagusia (1978)

\begin{tabular}{|c|c|c|}
\hline 1 & Abusu & Barrio de La Peña \\
\hline 2 & Araba Etxea & Casa alavesa \\
\hline 3 & Ardoa Barrura & Barrio de Indautxu \\
\hline 4 & Arrainak & PCE-EPK \\
\hline 5 & Atxuritarrak & Barrio de Atxuri \\
\hline 6 & Bizizaleak & Ecologistas \\
\hline 7 & Ganorabako & Desconocido \\
\hline 8 & Kezkalariak & Rekalde \\
\hline 9 & La Cubiertina Precoz & Rekalde y Uretamendi \\
\hline 10 & Mahats-Herri & Barrio de Begoña \\
\hline 11 & Hontzak & CNT \\
\hline 12 & Pinpilinpauxa & Apoyo a EHGAM y COPEL 20 \\
\hline 13 & Pirikiturris & Barrio de Zabalburu \\
\hline 14 & Rekalde & Barrio de Rekalde \\
\hline 15 & Samasiku & Barrio de Santutxu \\
\hline 16 & San Francisco & Barrio de San Francisco \\
\hline 17 & Satorrak & LCR-LKI \\
\hline 18 & Tomate Egileak & Barrio de Deusto \\
\hline 19 & Tintigorri & Barrio de Arangoiti \\
\hline 20 & Tximboak & Barrio del Casco Viejo \\
\hline 21 & Txintxarri & Bolueta y Otxarkoaga \\
\hline 22 & Txomin Barullo & MC-EMK \\
\hline 23 & Uribarri Gure Sule & Barrio de Uribarri \\
\hline 24 & Yeiki & Barrio de Cruces \\
\hline
\end{tabular}

Fuente: elaboración propia a partir de informaciones de la prensa local.

La Gaceta del Norte fue dando puntual noticia del proceso de formación de las comparsas. A comienzos de agosto todavía se pensaba que no pasarían de ocho. Pero rápidamente fueron surgiendo nuevas, hasta llegar a las 24 que finalmente tomaron parte ${ }^{21}$, conformando

${ }^{20}$ Euskal Herriko Gay Askapen Mugimendua (EHGAM), Movimiento por la Liberación Gay del País Vasco. Surgió en Bilbao a comienzos de 1977. Mantuvo estrechas relaciones con la Coordinadora de Presos en Lucha (COPEL), a favor de la derogación de la Ley de Peligrosidad y Rehabilitación Social.

${ }^{21}$ La Gaceta del Norte, 1-19 de agosto de 1978. 
un tejido social de más de 1.500 personas. La relación final de comparsas (tabla 1) parece reflejar un predominio de los grupos de barrios sobre los directamente vinculados a partidos políticos o sindicatos. No obstante, dentro de esos colectivos locales había numerosos militantes de la oposición antifranquista y de formaciones como el propio EMK. Algunas de esas comparsas pioneras aún siguen existiendo. Es el caso de Bizizaleak, Hontzak, Pinpilinpauxa, Satorrak, Tintigorri, Txomin Barullo y Uribarri ${ }^{22}$.

Apenas una semana antes del inicio, la comisión encargó a la artista bilbaína Mari Puri Herrero la realización de un personaje que habría de servir como seña de identidad y símbolo compartido. Así nacía Marijaia, una mujer de cuatro metros de altura, con los brazos alzados en actitud festiva y maternal, que apareció por sorpresa en el primer acto.

Imagen 7. La primera Marijaia en el Arenal de Bilbao, 20-08-1978. AMB. Fondo de La Gaceta del Norte

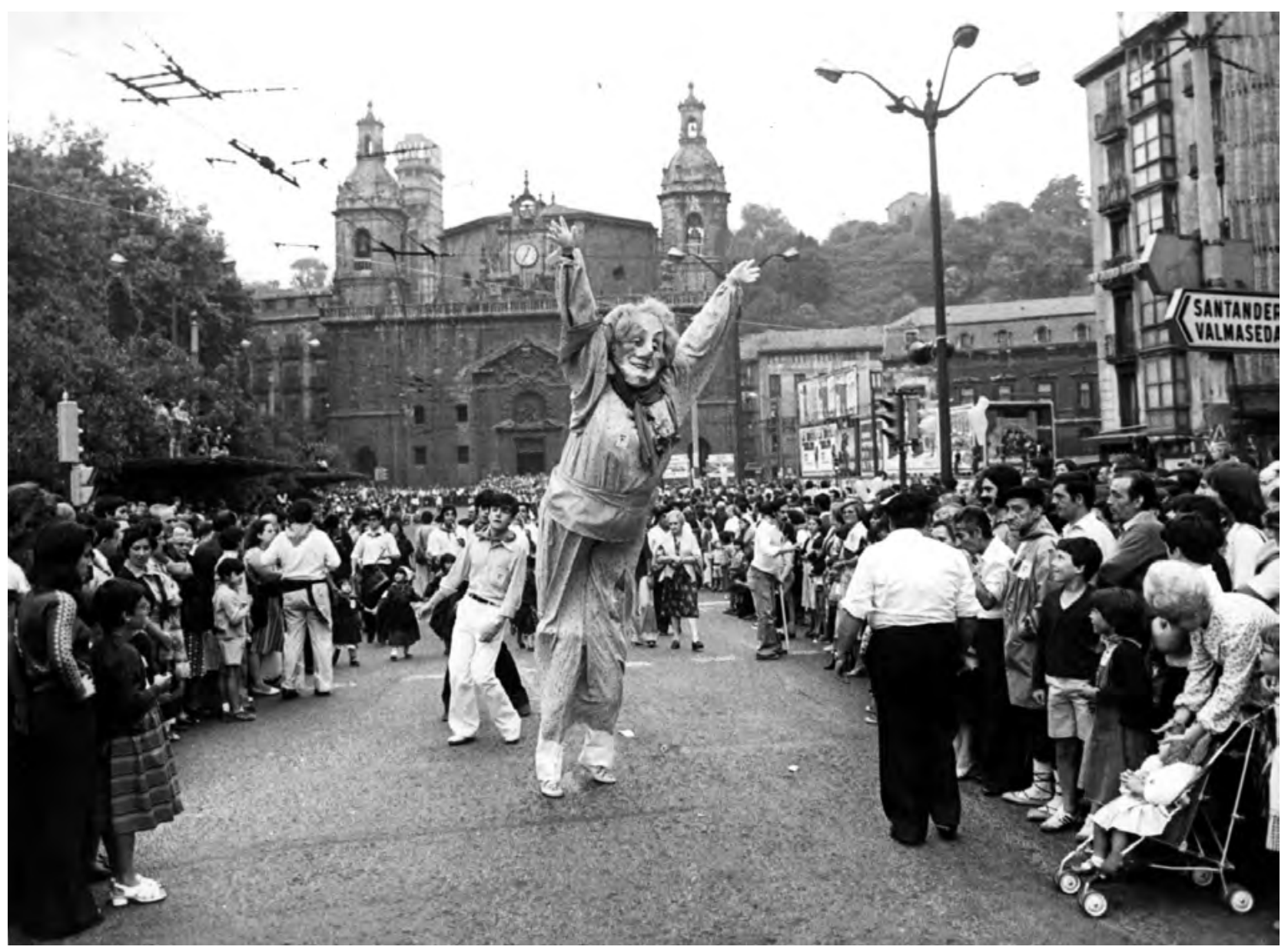

Por fin, la tarde del 19 de agosto se disparó el chupinazo que destapó el jolgorio colectivo:

Muchos miles de personas asistieron ayer, en Begoña, a la ceremonia de lanzamiento del «chupín» que anunciaba las fiestas populares de Bilbao. La iniciativa ha

22 http://www.bilbokokonpartsak.eus/es/ 
tenido mucha mayor acogida de la que se esperaba. Bandas de cartón, comparsas, grupos de danza y numeroso público comenzaron a bailar y danzar cuando la «chupinera» lanzó por los aires de Bilbao el cohete mágico. Y se inició la bajada de Begoña al Arenal con cuarenta y cuatro grupos que saltaron y animaron el recorrido. En el Arenal, centro neurálgico de las fiestas, se unió a la «bajada» un gentío inmenso. Se leyó el pregón y se lanzaron fanfarrias y comparsas a la sana alegría que quiere inundar de fiesta al «Bocho» ${ }^{23}$.

Álvaro Gurrea hizo una descripción un tanto irónica del cortejo de «Txomin Barullo»: «Era ridículo ver a tanto militante de extrema izquierda, líderes obreros, de asociaciones de vecinos, antiguos pistoleros, mujeres feministas, convertidos todos de repente en una especie de espantoso grupo de danzas» (Golvano, 2004: 101).

Imagen 8. Banda de cartón de la comparsa de La Peña, 4-08-1978. AMB. Fondo de La Gaceta del Norte

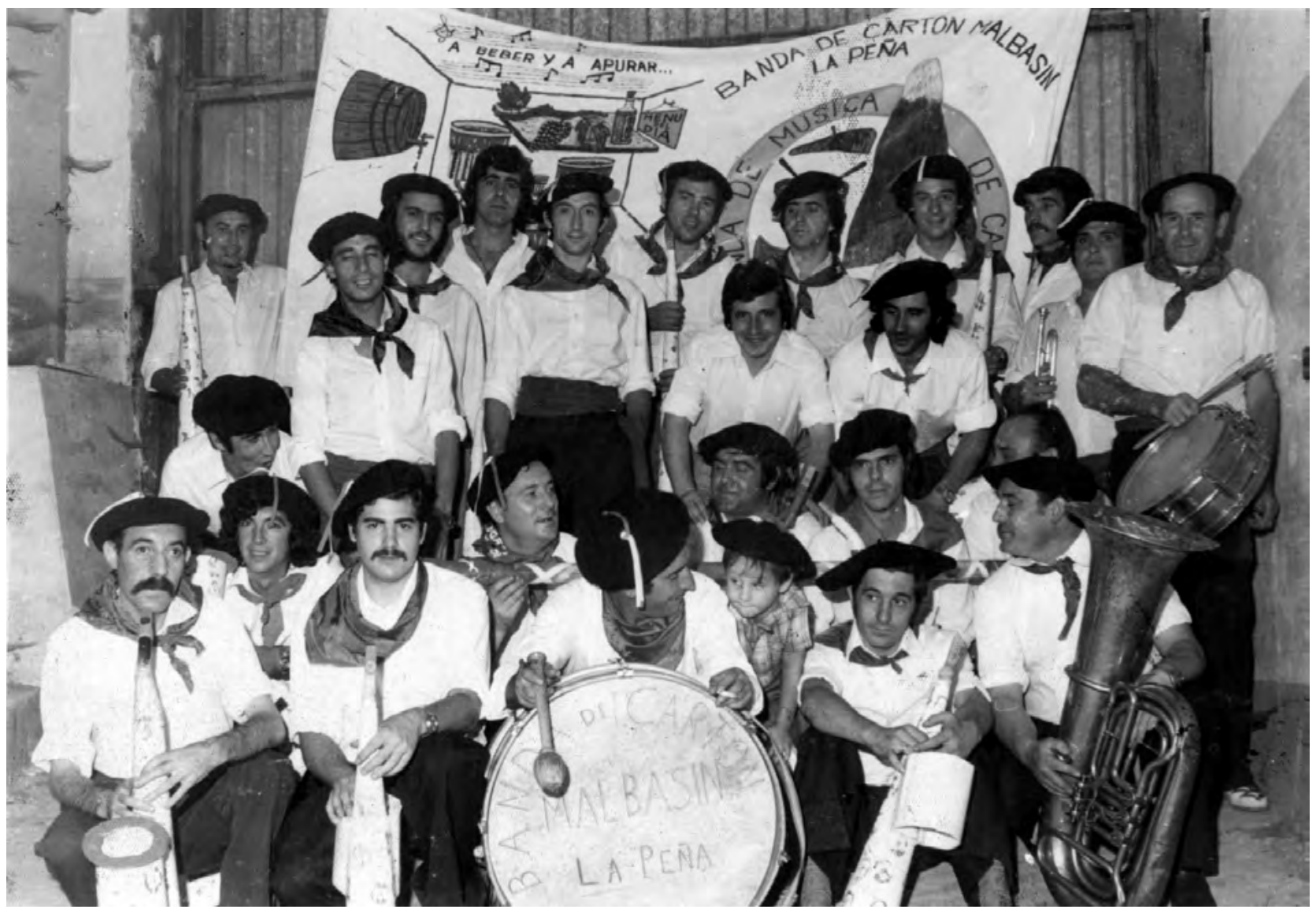

\section{LA FIESTA ERA UN GRAN CARTEL}

El teórico de la cultura Mijail Bajtin escribió que las fiestas oficiales «no sacaban al pueblo del orden existente, ni eran capaces de crear esta segunda vida. Al contrario, contribuían

${ }^{23}$ El Correo, 20 de agosto de 1978. 
a consagrar, sancionar y fortificar el régimen vigente» (Bajtin, 1971: 15). Es decir, ratificaban la inmutabilidad de las normas, la apariencia de armonía social, el consuelo paliativo de un paréntesis efímero antes del ineludible retorno a las tareas cotidianas. Estas fiestas regularizadas están situadas en las antípodas del caso bilbaíno del 78, creadas esta vez "al margen de todo oficialismo" ${ }^{24}$. Siendo, incluso, una parodia iconoclasta del oficialismo, una relativización de la autoridad, una inversión del orden establecido, un quebrantamiento de la ortodoxia. Con alcalde y concejales de vacaciones veraniegas, los miembros de la comisión de fiestas entraban y salían a placer de la Casa Consistorial, con un técnico municipal como interlocutor. «Nunca estuvo Bilbao tan cerca del ideal de república libertaria, Txomin Barullera y Groucho-marxiana como en aquel mágico, legendario e irrepetible momento» (VVAA, 1993: 12).

Durante nueve intensos días, los barrios se volcaron sobre el centro de la villa. En palabras de Álvaro Gurrea, «llegamos a creer que habíamos hecho una especie de revolución y en cierto modo sí que la hicimos, al menos desde ese punto de vista situacionista (mayo del 68, etc.) de la revolución aquí y ahora» (Golvano, 2004: 99). A pesar de la improvisación y la velocidad de los preparativos, las fiestas conectaron con el sentir popular, con un ánimo latente, que emergió desde los márgenes legales a los que había quedado desplazado, desde la periferia al centro de la vida pública.

El Correo recogió en su portada del 23 de agosto que los mozos tenían que reponer «el vino que se consume en las txoznas en cantidades realmente espectaculares. Durante el pasado fin de semana se agotaron prácticamente todas las existencias de vino (alrededor de 40.000 litros) a lo que hay que añadir el consumo de otros 40.000 litros de diversos tipos de bebidas y 120.000 de refrescos». Y para comer, «nada menos que 50.000 barras de pan, 300 kilos de chorizo, 200 de patatas entre otras cantidades igualmente respetables de condimentos para reponer fuerzas» ${ }^{25}$. Había una excepción: la txozna de la comparsa «Bizizaleak», que agrupaba al colectivo ecologista, no servía alcohol.

Pese a su ritual aparentemente inofensivo, no estamos ante expresiones de hedonismo simplemente lúdicas, destinadas al relajamiento o a la evasión pasajera, sino que bajo ciertas circunstancias históricas adquirían un sentido de la crítica muy acentuado, un tono de protesta. Era habitual ver «todo tipo de pegatinas y carteles alusivos a la vida política o a problemas municipales (...). También los grupos antinucleares y ecologistas han aprovechado la oportunidad para difundir sus planteamientos, muy concretamente contra la central nuclear de Lemóniz» ${ }^{26}$. Diversas organizaciones políticas constituyeron comparsas y sacaron a la plaza pública sus propuestas. Pero en plena crisis de transición, más que hacer política en la fiesta, la fiesta popular ya representaba una transgresión. Como proclamaba el pregón:

\footnotetext{
${ }^{24}$ Egin, 19 de agosto de 1978.

${ }^{25}$ El Correo, 23 de agosto de 1978.

${ }^{26}$ El País, 20 de agosto de 1978.
} 
Imagen 9. El País, 29 de agosto de 1978. Este diario, símbolo del cambio político y social durante la transición, llevó a su contraportada un balance de la primera Aste Nagusia

\section{ELPAIS}

\section{SUMARIO \\ "Gmapos": veintiséis dias en huelga dehambre}

Los veinticinco miembros de los GRAPO que permanecen en hueiga de hambre en la prisión de Soria están en la prision de Soria están grave estado de salud.

Pagina 10

\section{Reunión del PSUC para evaluar el cese de Pere Comas .}

El comité ejecutivo del Barcelona para masiderar cese del secretario genera cese del secretario general Sanidad de Catalun̂a, Pere
Comas, decretado por el presidente Tarradellas.

\section{Confusión en tomo al casino} de Madrid

Mientras el Ministerio de Interior guarda silencio so. bre los motivos que hicieron anular la licencia de construcción del Casino Gran Madrid, el gerente de nada oficialmente

Pagina 13

\section{Nuevos cargos \\ en Televisión}

Española

y Radio Nacional

Los periodistas Miguel Martia y Luis Angel de la Viuda han sido nombrados directores de Televisión Es. pantola y de Radio Nacional de Espana,
Pagina 15

\section{Ricando Tormo, \\ campeón \\ del mundo}

de motociclismo

Tras imponerse en el Gran Premio de Checosiovaquia, el espanol Ricardo Tormo dial en la categoria de $50 \mathrm{ccc}$. Pigina 24

\section{Secciones}

\section{iNTERACIONaLz}

OPINION/A POUTICA/\& EEGIONESIIL.MADRIDIIR SOCLEDADIX

ACOLTURAOAT CAPRCTACULOSIR
CARNET/ZO CARTELERA/72 CARNET/BO CARTELERA/IZ

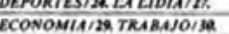
EOLSAIII.

CUPON PRO CUPON
CIEGOS
Hace tan sólo un año Bilbao no tenia fiestas, al menos entendidas como la oportunidad que tiene un pueblo para divertirse colectivamente. Habia toros y poco más. Incluso los fuegos artificiales y verbenas se dejaron perder como festejos impropios de una ciudad. De pronto, un concurso de ideas y un programa elaborado por el colectivo Txomin Barullo. del Movimiento
Comunista de Euskadi, han bastado para poner patas arriba la ciudad durante nueve días en una cadena de charangas que han movilizado cerca de un millón de personas. Los organizadores de las fiestas estiman que éstas han sido una importante experiencia autogestionaria, demostrativa de la capacidad del pueblo para organizarse.

Jesús Ceberio nos lo cuenta.
En ellas intervinieron más de un millón de personas

\section{La fiestas populares de Bilbao, un éxito de la espontaneidad}

Nunca nadie, con sôlo nueve dias de historial tuvo un entierto tan multitudinarionitan sentido como carnes, con cara de cachondes cuerpode jota acidade las manos de la pintora Mari Puig Herrero, Mari Jaia no ha sido un simbolo ni una maseota, fue la fiesta mismade Bilbao, que se quemó el domingo medianoche mientras su e ataudd amarillo se hundia en la ria ante no menos de 50000 personas. Este fue el ûnico rito funerario de unas fiestas que hace un ano no existian y que han movilizado po encima de las 100,000 personas diarias. Los de Txomin Barullo hicieron el programa, pero las fiestas las lome el pueblo, diriase con afa de revancha sobre cincuenta ahos de no fiestas, de miedo a la calle. Alvaro Gurrea. economista, uno de los créadores del grupo, lo ex. plica asi: - nosotros no hemos in do a una tradición que eataba presente, aunque no se ejerciera. Los vascos nos hemos divertido siem. pre cantando y brincando por la calle y eso, que no viene en ningùn programa de fiestas, es lo que not preocupaba. Algo asi como las palmas en Andalucia. Par conseguirlo creimos que no habí la gente en un sitio. Para eso se instalaron las casetas, juntas, en el Arenal.

Todos coinciden en que unir a toda la ciudad en un pequeño es. pacio en torno a su casco viejo, h jugado un papel multiplicador. Juan Carlos Eguillor, abogado de
todos los cachondeos, cree que la gente atiene necesidad de solgar. Para el, estas fiestas han significado, sobre todo, una liberación cor poral, - Nos bemos dado cuenta de que para manifestarnos no hay que if necesariamente detrás de un pancara. Hemos visto que et cuermunicarie. Lo importante no era programa sino salir a la calle y ponerse a bailar."

Para los de Txomin Barullo esta ocupación del centro de la ciudad tiene incluso una virtualidad revolucionaria: ees dificil querer un ciudad en la que se vive solo el in framundo del suburbio. Las fiestas han hecho posible el disfrute de una zona urbana privilegiada, que se cuida con los impuestos de todos y que suele estar rest.

Un sociólogo, Alfonso Pére Agote. cree que ha sido una toma moria de las personas, unas fiesta son mucho mass que una semana. incluso diria mas importantes que el pan. Trabajamos en un sitio, pero volvemos siempre a las fiestas de nuestro pueblo. La identidad territorial de las personas esta muy li. guramente la imagen de Bilbaio no

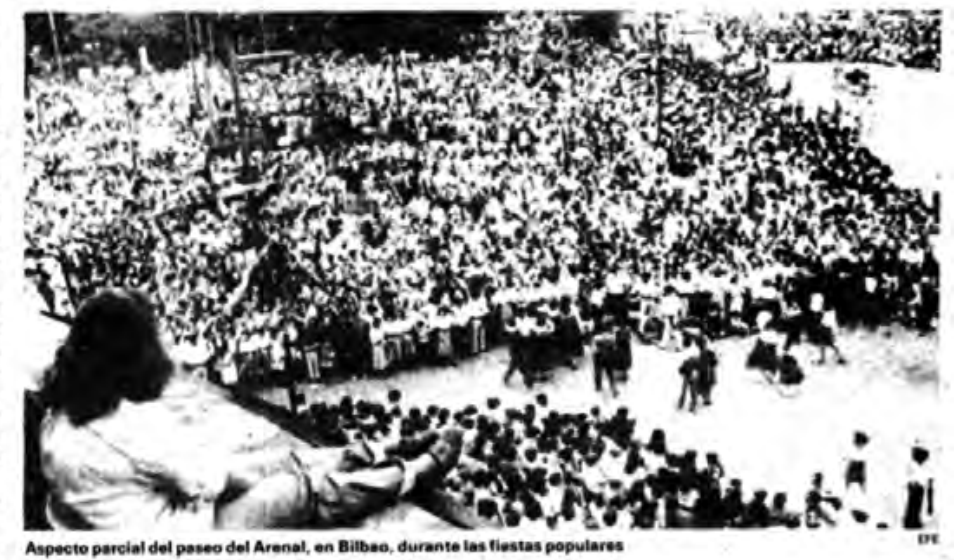

hace una semana hay una emoción nueva, que antes sôlo podia existit por omisión.

Bailar juntos, apretados si cabe, ha sido uno de los factores que han hecho de esta ailtima semana granun nivivel comparable con los sar a ermines. Algunos han acusado de copiar descaradamente a Pamplona. ANo creo -dice Burrea- que ninguna ciudad pueda reivindicat la tradición de cantar y bailar en la calle, por que eso es de todos los y y comparsas tiene, por otra parte, cn Bibas, wna tradicion de al me-

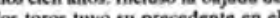
desfile de las carrozas de los pode rosos que iban a la plaze, solo que entonces la gente de alpargata eran meros especiadores desde las ace ras y ahora han pasado a ser los proiagonistas. Hubo, en efecto, elementos incorporados de Pam. plona o de otros sitios, pero en lodo caso creo que se trata de tradiciones festivas asumidas por todo $\mathrm{el}$ pueblo vaseo y que en el caso de Bilbao han tenido su propia perso. nalidad.*

La importancia del vino

Para bien o para mal, el vino ha ido un elemento casi tan imporAnte como el propio baile. Pérez os laciedades primitivas se han servido siempre de recursos artifciales para evadirse de una real dad que no les gustaba. La droga de el alcohol. En una sociedad tan dramatizada, con la violencia co. mo constante desde hace al menos 150 años, no es extranto que necesiIemos una cierta dosis de vino para quitar el miedo y expresarnos con hbertad. Lo terronifico seria que ef alcohol se convirtiese en la meta de la fiesta. Nocreo que haya sido cste
Borracheras las ha habido de toJos los tamaños y profundidades. Thl vez por eso Juan Carlos Eguilor diga que se trata de eunas fiesas barbarass, para anadir a contipuación que eso no es malos. Lo mportante para el es que la gente chaya deshinbido. Cada cual es dueno de emplear el metodo que prefiera. Llo que nuaca crei Jura como Bibao, en una sociedad an vion ese pudor que dicen que tenemos, a la calle el sabado con un disiras que en casi lodos los casos culaba ech por tllos mismos. De repen. y ha caido en la cuenta de que ese noes un privilezio de los elezidoso. Por supuesto que la politica no puede decirse que las fiestas han sido vascas hasta el final. El persohaje mas mentado fue sin duda Martin Villa y la canción de évitio mas contiouado decla que rove vayan, que se vayan, que se vayan de una puta vez, que se vayan, que se vayan, que se vayan para no Urrea ahade, por su parte, que la politica no ha sido un elemento de quisiba, sino que ba contribuido a queble y a que nos subamos al pueblo y a ques subarios al vensiones entre las distintas capillas politicas han side muchas veces provocadas - idea en la que apunta Equillor - y que la comunicación que hubo estos dias puede contribuir a suavizarlas. eNo cabe duda de que la comunicacion y mucho mas si es insica, potencia la solid. ndad.

Alvaro Gurrea insiste, sin en bargo, en que estas fiestas no han mo un tubo de escape de una sederepente 0000 personas saliesen ha estado ausente. También en eso

Experiencia autogestionaria

mana para que la gente se este quieta el resto del afóo. Eso sería a trampa. Nosotros hemos traado tan sólo de que la gente dopierte sas ganas de fiesta, sin abdicar de nada. La lucha no est. renida con el juego. Ademas, creeTor que esta ha sido una experienca alogetionaria imporance. Ante nueve dias y el pueblo ha de mestrado das y el puebio ha de. morranizarse Si husta a bora ao lo. habia hecho es porque nole habias dejado y si no lo puede hacer en tros campos es por la misma

Se preguntara alguien, despues

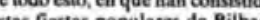
Espectículos aparic, fue los bubo buenos la fiesta la han hecho los 
La fiesta hará que la vida eche raíces en el mismo cemento y que hasta los adoquines nos lo vayan a agradecer. El hombre-asfalto no ha aceptado jamás la derrota y demuestra, como ahora, que aún tiene mucho que decir y que hacer (...). No queremos, en absoluto, que todo esto resulte únicamente una válvula de escape, un mero respiradero por el que oxigenar una existencia monótona y gris durante el resto del año. En los más simples hechos cotidianos existen elementos importantes de júbilo y de juego. (VV.AA., 1993: 2)

La primera Aste Nagusia de Bilbao persiguió alcanzar «otro estilo de vida que está aún por estrenar, anuncio también de esa otra sociedad que intuimos, a veces emocionadamente, en la que el placer fuera mil veces más fuerte que el dolor» (VV.AA., 1993: 2). En el verano de 1978, alrededor de las fiestas se construyó un espacio libre, entendiendo por tal no un lugar marginal, fuera de la sociedad, para mayor comodidad de un grupo determinado, sino un ámbito autónomo del poder (que, en el caso de los ayuntamientos, aún no era democrático), donde las personas podían expresar identidades múltiples (Polletta, 1999). Un espacio plural, con vocación extensiva hacia el conjunto social y no solo hacia una parte del mismo.

\section{CONCLUSIONES}

La fiesta popular, tras tiempos de moral rectilínea y ascesis obligatoria, tras 40 años de prescripciones, solemnidad y abstinencia impuesta, vino a sacudir los viejos moldes con su irreverencia, con su espíritu burlesco, participativo y crítico. Las respetables virtudes anteriores se ahogaron en un torrente desenfrenado (e inverosímil hacía bien poco); en una catarsis colectiva (con todo lo que tiene de rito purificador), rompiendo con el tono gris y el perfil cerrado de la fiesta a la que sustituyó. Unas fiestas «bárbaras», presididas por un tono de liberación corporal, del cuerpo individual y del cuerpo social. "Nos hemos dado cuenta de que para manifestarnos no hay que ir necesariamente detrás de una pancarta —decía Juan Carlos Eguillor a El País-. Hemos visto que el cuerpo sirve para expresarse, para comunicarse. Lo importante no era el programa sino salir a la calle y ponerse a bailar». En fin, «los de «Txomin Barullo» hicieron el programa, pero las fiestas las tomó el pueblo, diríase con afán de revancha sobre cincuenta años de no fiestas, de miedo a la calle» ${ }^{27}$. Este sentido de protesta carnavalesca viene reforzado por el hecho, no casual, de que fueran las mismas comparsas las que, desde esas fechas (a partir de 1979), también organizaron y relanzaron el carnaval urbano bilbaíno. Un carnaval que había quedado silenciado durante el franquismo, como prohibido había estado el uso de máscaras.

En la primera Aste Nagusia se produjo una confluencia de varios factores que explican el «inimaginable éxito» de la convocatoria. Un contexto especial, una organización flexible e

${ }^{27}$ El País, 29 de agosto de 1978. 
integradora, y un amplio deseo popular de divertirse y expresarse, de dejar atrás oscuros tiempos para lanzarse con esperanza hacia otra etapa aún en construcción. El EMK era entonces una fuerza política relativamente potente, con jóvenes militantes muy activos, y de su esfuerzo, al que se fueron sumando otros muchos, surgieron aquellas fiestas, que también se beneficiaron de la experiencia profesional de diferentes miembros de la comisión organizadora (en ámbitos como la música, el teatro o el urbanismo), que tuvieron que poner todo en marcha contrarreloj.

La comisión y las comparsas decidieron dar continuidad a sus actividades. Sin embargo, las fiestas, tal como fueron concebidas y desarrolladas en agosto del 78, supusieron un momento irrepetible. Desde entonces se siguen celebrando, también masivas y alegres, pero bajo otras circunstancias. Las elecciones municipales de abril de 1979 supusieron la democratización de los ayuntamientos. A partir de ahí se produjo un rápido desgaste del movimiento vecinal, que hay que enmarcar en un proceso más amplio de crisis del asociacionismo voluntario y de desmovilización progresiva.

Un segmento político sí permaneció constantemente movilizado, en este caso bajo premisas inciviles: el nacionalismo vasco radical. A partir de la transición, muchas comisiones de fiestas, así como otras expresiones sociales, fueron "vampirizadas» por dicho sector (Casquete, 2009), que no las utilizó para construir espacios libres, sino otros en los que dominaba la apología del terrorismo: pegatinas, fotografías, pintadas, manifestaciones o comidas en honor a los miembros de ETA, mensajes de odio hacia la Policía o contra los oponentes políticos, etc. Como muestra, valgan dos botones. Uno, la "guerra de las banderas", unos graves disturbios que se repitieron durante años contra el izado de la enseña de España en el Ayuntamiento de Bilbao en el día grande de las fiestas. Y dos, la brutal paliza propinada al ertzaina Ander Susaeta por una docena de jóvenes radicales durante la Aste Nagusia de 1993.

En 1978 ya había empezado la espiral de violencia; de hecho, puede considerarse que los años de plomo arrancan en ese punto. Algunas consignas y canciones muy coreadas en las fiestas patronales, también en la Semana Grande, mostraban claramente el resentimiento que anidaba en una parte de la población e incluso la banalización del asesinato político. Por ejemplo, el «que se vayan» (dedicado a las FOP) o el «Carrero voló», celebrando el atentado de ETA que costó la vida en 1973 al presidente del Gobierno franquista, el almirante Luis Carrero Blanco. Pero aún desconocíamos las trágicas dimensiones que alcanzaría esa espiral. Entonces aún se podía esperar que la consolidación de la democracia acabaría con el terrorismo y que empezaría un nuevo tiempo de alegría y, sobre todo, de libertad para todos. 
Imagen 10. La quema de Marijaia marcó el final de la Aste Nagusia, 29-08-1978. AMB. Fondo de La Gaceta del Norte

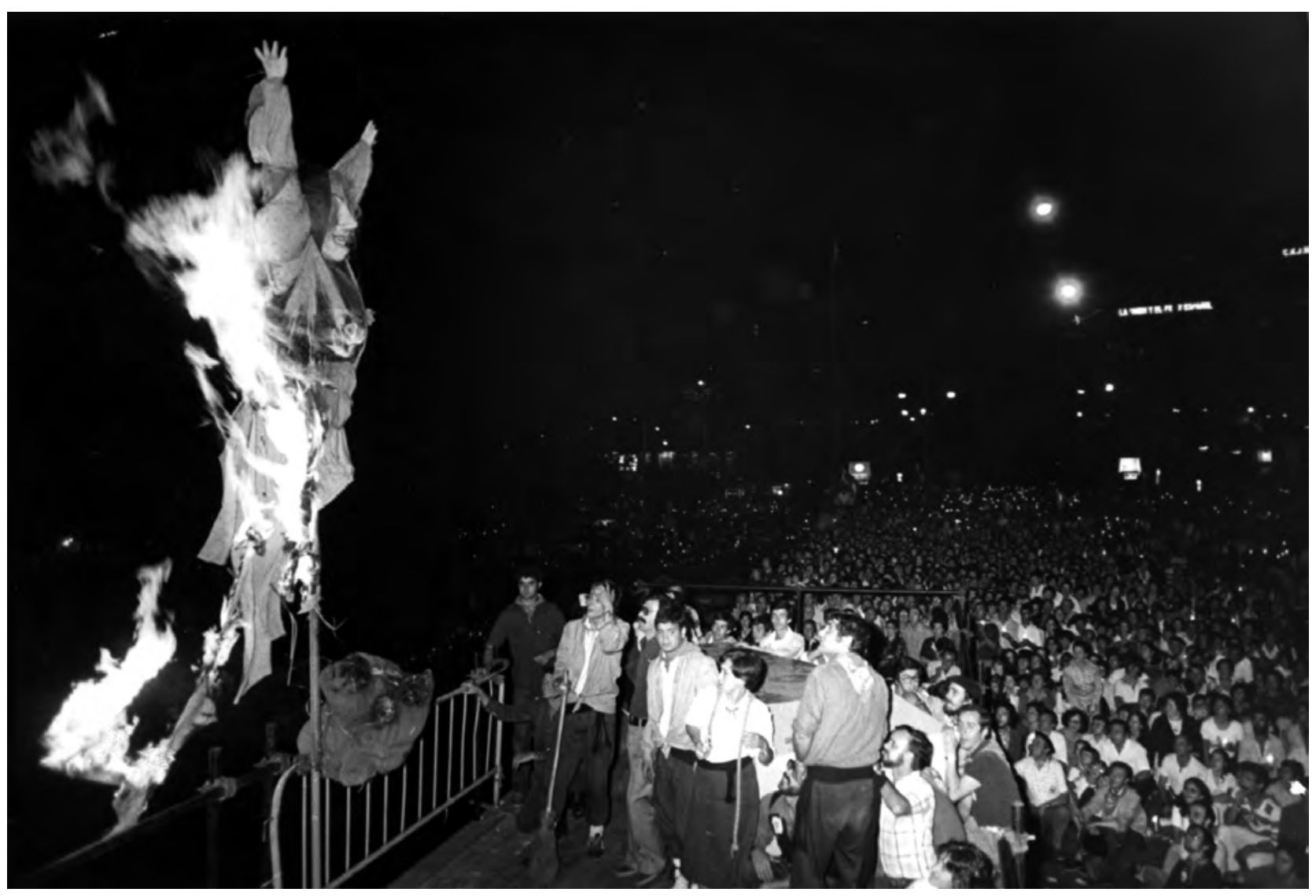

\section{REFERENCIAS BIBLIOGRÁFICAS}

Aizpuru, M. (1998). Asociacionismo popular. ¿Reverso del modelo de organización social del franquismo? El caso de Barakaldo. En Castillo, Santiago y José M. ${ }^{a}$ Ortiz de Orruño (eds.), Estado, protesta y movimientos sociales. Bilbao: Universidad del País Vasco, pp. 477-494.

Asociación de Familias de Recaldeberri (1975). El libro negro de Recaldeberri. Barcelona: Dirosa.

Bajtin, M. (1971). La cultura popular en la Edad Media y Renacimiento. Barcelona: Barral.

Burke, P. (1991). ¿Qué es la historia de la cultura popular?, Historia Social, n. ${ }^{\circ}$ 10, pp. 153155.

Casquete, J. (2009). En el nombre de Euskal Herria. La religión política del nacionalismo vasco radical. Madrid: Tecnos. 
Castells, L. (2017). La transición en el País Vasco (1975-1980). En Fusi, J. P. y J. A. Pérez (eds.), Euskadi 1960-2011: dictadura, transición y democracia (pp. 67-89). Madrid: Biblioteca Nueva.

Egiraun, J. y J. del Vigo (2007). Rekaldeberri: desarrollismo y movilización vecinal. En Martínez Rueda, F. (coord.), Bilbao y sus barrios: una mirada desde la historia (pp. 105139). Bilbao: Ayuntamiento de Bilbao, Vol. I.

Fusi, J. P. (1986). La reaparición de la conflictividad en la España de los sesenta. En Fontana, J. (ed.), España bajo el franquismo (pp. 160-169). Barcelona: Crítica.

Golvano, F. (2004). Disidencias otras. Poéticas y acciones artísticas en la transición política vasca: 1972-1982. San Sebastián: Diputación Foral de Guipúzcoa.

Gracia Cárcamo, J. (1995). Microsociología e historia de lo cotidiano, Ayer, n. 19, pp. 189222.

Heine, H. (1986). La contribución de la «Nueva Izquierda» al resurgir de la democracia española, 1957-1976. En Fontana, J. (ed.), España bajo el franquismo (pp. 142-159). Barcelona: Crítica.

Homobono, J. I. (1982). Espacio y fiesta en el País Vasco, Lurralde, nº 5, pp. 91-120.

Levi, G. (2003). Sobre microhistoria. En Burke, P. (ed.), Formas de hacer historia (pp. 119143). Madrid: Alianza.

López Romo, R. (2011). Años en claroscuro: nuevos movimientos sociales y democratización en Euskadi. Bilbao: Universidad del País Vasco.

López Romo, R. (2015). Informe Foronda: los efectos del terrorismo en la sociedad vasca. Madrid: Los Libros de la Catarata.

Molinero, C. e Ysàs, P. (1992). Movimientos sociales y actitudes políticas en la crisis del franquismo, Historia Contemporánea, n. ${ }^{\circ}$ 8, pp. 269-280.

Pérez Pérez, J. A. (2001). Los años del acero: la transformación del mundo laboral en el área industrial del Gran Bilbao, 1958-1977: trabajadores, convenios y conflictos. Madrid: Biblioteca Nueva.

Pérez-Agote, Alfonso (1987). El nacionalismo vasco a la salida del Franquismo. Madrid: CISSiglo XXI.

Polletta, F. (1999). «Free spaces» in collective action, Theory and Society, n. ${ }^{\circ}$ 28, pp. 1-38. 
¿Espacios libres en (la) transición? La primera Semana Grande de Bilbao | Raúl López Romo

Ramírez, E. (1984). Cuadrillas en el País Vasco. Identidad local y revitalización étnica, REIS, n. ${ }^{\circ} 25$, pp. 213-222.

Toral, M. (ed.), textos de G. Fernández Soldevilla. La calle es nuestra: la transición en el País Vasco (1973-1982). Bilbao: Kultura Abierta.

Urrutia, V. (1985). El movimiento vecinal en el área metropolitana de Bilbao. Oñate: IVAP.

VV.AA. (1993). Gora Aste Nagusia! 15. Urteurrena. Bilbao: Ayuntamiento de Bilbao. 